ISSN 1823-626X

Journal of Fundamental Sciences

available online at http://jfs.ibnusina.utm.my

\title{
Optimization of lipase-catalyzed synthesis of flavour esters in solvent free system
}

\author{
Syamsul Kamar Muhamad ${ }^{1}$, Salina Mat Radzi ${ }^{1 *}$, Siti Salhah Othman ${ }^{1}$, Mohd Basyaruddin Abdul Rahman ${ }^{2}$ and Hanina Mohd Noor ${ }^{1}$ \\ ${ }^{1}$ Faculty of Science and Technology, Universiti Sains Islam Malaysia, Bandar Baru Nilai, 71800 Nilai, Negeri Sembilan, Malaysia. \\ ${ }^{2}$ Chemistry Department, Faculty of Science, Universiti Putra Malaysia, 43400 UPM Serdang, Selangor, Malaysia. \\ Received 17 February 2010, Revised 4 April 2010, Accepted 19 April 2010, Available online 25 May 2010
}

\begin{abstract}
The effects of important reaction parameters for enhancing flavour esters formation through lipase-catalyzed reaction were investigated in this study. Various commercial immobilized lipases were used to catalyze the esterification reaction between short-chain fatty acids and alcohols to produce flavour esters which are nonyl caprylate and ethyl valerate which differ in chain length of esters. These synthetic flavour esters with fruity notes are widely used in food, cosmetic and pharmaceutical industries. The effect of various reaction parameters was optimized to obtain a high yield of flavour esters. A maximum percentage for nonyl caprylate with conversion of flavour esters more than $90 \%$ in a solvent-free system was successfully obtained under the following conditions: reaction time (RT), 5 hours; reaction temperature, $40{ }^{\circ} \mathrm{C}$; amount of immobilized lipase, $25 \%$ w/w of total substrate and shaking speed $200 \mathrm{rpm}$. Compared to ethyl valerate, a maximum percentage conversion of flavour ester more than $80 \%$ in solvent free system was successfully obtained under following conditions: reaction time (RT), 45 minutes; reaction temperature, $40{ }^{\circ} \mathrm{C}$; amount of immobilized lipase, $15 \%$ w/w of total substrate and shaking speed $200 \mathrm{rpm}$. Comparison between these two ester showed that the chain length give an effect to optimize the reaction condition in esterification reaction.
\end{abstract}

| Enzyme | Lipase | Esterification | Optimization |

( 2010 Ibnu Sina Institute. All rights reserved. http://dx.doi.org/10.11113/mjfas.v6n1.172

\section{INTRODUCTION}

Flavour ester, a short-chain ester is a class of compound that widely distributed in nature. This kind of ester also known as a carboxylic acid ester is extensively used in foods, beverages, cosmetics and pharmaceutical industries. Flavour esters are fine organic compound that forming part of natural aromas in flowers and fruits. Traditionally, these compounds has been isolated from natural sources such as flowers, fruits and vegetables. However, these natural flavour esters extracted from plant materials are often limited and expensive for commercial use. Thus, it is economically important to synthesize flavour ester using cheaper and more broadly available material to meet the consumer demand [1].

The worldwide market for natural green notes is estimated to be 5-10 metric tones per year [2]. For example, demand for flavuors and fragrances in the US are forecast to grow 3.7 percent per year to $\$ 5.3$ billion in 2012. Increasing consumer interest in natural ingredients, which are generally more expensive than their synthetic counterparts, will support value gains. Also, trends toward more complex and exotic flavours and scents will boost demand for new flavour and fragrance blends.

Corresponding author at: Faculty of Science and Technology, Universiti Sains Islam Malaysia, Bandar Baru Nilai, 71800 Nilai, Negeri Sembilan, Malaysia.

E-mail addresses: salina@usim.edu.my (Salina Mat Radzi)
Food will remain the largest market for flavours and fragrances, based on the widespread application of flavour materials in many processed food.

Conventional chemical synthesis of flavour ester between acid and alcohol using polluting liquid acids as a catalyst, require post-treatment. Thus, the use of biotechnology appears to be an attractive in various ester preparations under milder conditions and the product may be given the natural label. Therefore, the use of enzymes, such as lipases as biocatalysts may offer many significant advantages over chemical synthesis such as lower energy requirement since enzymes function under mild reaction conditions and enhanced selectivity and quality of product. There are a number of publications regarding the enzymatic synthesis of flavour esters in non-conventional media, particularly in the presence of solvents [1-3]. However, the number of articles that discussed the enzymatic synthesis in solvent free systems is considerably low [4].

The use of native lipase form brings about significant practical problems such as the high cost of the enzyme. As a mean of reducing the cost, the use of immobilized lipases is significantly advantageous. Immobilized lipase are lipases attached to solid materials, which make them easily be recovered from the reaction mixtures, thus offers reutilizations of the biocatalyst and thereby making the process economically feasible [5]. Another aims of using immobilized lipase is the functional activities as well as the 
stability of enzymes are improved compared to the native lipase.

A better understanding of various reaction parameters affecting the esterification with short-chain substrates is essential for possible large scale synthesis. This paper shows a high performance synthesis of flavour esters by enzymatic synthesis route using an immobilized lipase in solvent free system (SFS).

\section{EXPERIMENTAL}

\section{$2.1 \quad$ Materials}

Novozym 435 as 10,000 PLU (from Candida antartica lipase immobilized onto macroporous acrylin resin), Lipozyme TL IM as 250 IUN/g (from Thermomyces lanuginosus immobilized onto granulated silica) and Lipozyme RM IM as 150 IUN/g (from Rhizomucor miehei immobilized onto macroporous anion exchange resin) was received from Novo Nordisk (Denmark). Ethanol (purity, 98\%), nonanol (purity, 99\%) valeric acid (purity, 99\%) and caprylic acid (98\%) were obtained from Merck (Germany). All other reagents were of analytical grade and used as received.

\subsection{Method}

\subsubsection{Ethyl valerate and nonyl caprylate synthesis}

The reaction system consisted of carboxylic acid and alcohol (1:1) and 5\% of enzymes (w/w) were mixed in a screw-capped vial. The mixture was incubated at $37{ }^{\circ} \mathrm{C}$ using a horizontal waterbath shaker. The shaking speed was set at $150 \mathrm{rpm}$ and the reaction mixture was continuously reacted for 12 hours.

\subsubsection{Analysis of reaction product}

Determination of the percentage conversion of ethyl valerate and nonyl caprylate (\%): The percentage conversion (\%) of ethyl valerate nonyl caprylate was measured by determining the remaining unreacted fatty acids in the reaction mixture by titration with $1.0 \mathrm{M} \mathrm{NaOH}$ in an automatic titrator (Methrom, Switzerland). All the samples were assayed in triplicate and the experiment was repeated twice.

Conversion of flavour ester $(\%)=$

Volume of $\mathrm{NaOH}$ (without enzyme) - Volume of $\mathrm{NaOH}$ (with enzyme) X 100 Volume of $\mathrm{NaOH}$ (without enzyme)

\subsubsection{Effect of reaction time}

The effect of time in the flavour ester synthesis was investigated by varying reaction periods $(5,10,15,30,45$, $60,90,120,150$ and 180 minutes for ethyl valerate) and (1, 2, 3, 4, 5, 6, 8, 10 and 12 hours for nonyl caprylate) while fixing the other conditions. The percentage conversion was determined as described above.

\subsubsection{Effect of temperature}

The reaction mixtures were incubated at various reaction temperatures $(30,35,40,45,50,55,60,70$ and $80^{\circ} \mathrm{C}$ ) while fixing the other conditions. Percentage conversion of flavour ester was determined as described above.

\subsubsection{Effect of amount of enzyme}

The reactions were studied using various amount of enzyme (5, 10, 15, 20, 25 and $30 \%(w / w))$ while fixing the other conditions. Percentage conversion of flavour ester was determined as described above.

\subsubsection{Effect of shaking speed}

The reaction mixtures were reacted with different shaking speed (50, 100, 150, 200 and 250 rpm) while fixing the other conditions. Percentage conversion of flavour ester was determined as described above.

\section{RESULTS \& DISCUSSION}

\subsection{Screening of immobilized enzymes}

Optimization of enzymatic synthesis of ethyl valerate and nonyl caprylate was carried out in screw-capped vials. A conventional method of varying one parameter-at-a-time is applied to obtain the optimum operating conditions. The effect of various parameters that influenced the reactions including temperature, time course, enzyme amount and shaking speed were studied. Preliminary study on screening of immobilized enzyme showed that novozym 435 gave the highest percentage conversion compared to lipozyme TLIM and lipozyme RMIM. As shown in figure 1, the highest percentage conversion of flavour ester using novozym 435 was $73 \%$ for ethyl valerate and $82 \%$ for nonyl caprylate. This explained that immobilized lipase from Candida antarctica, Novozym 435 have the specificity to form an ester bond. As reported previously [6], Novozym 435 is the most commonly used lipase in biocatalysis and it promotes the reaction between a wide range of primary and secondary alcohols and carboxylic acids. It is a highly versatile catalyst with activity towards a great variety of different substrates.

\subsection{Effect of reaction time}

The time course is a good indicator of enzyme performance and reaction progress. It can determine the shortest or adequate time necessary to obtain a good yield and minimize the process cost. Figure 2 shows the reaction time profile for the esterification reaction of valeric acid with ethanol and caprylic acid with nonanol catalyzed by 
Novozym 435. Experiments at nine different times were carried out to analyze its influence on the esterification reaction.

The rate of reaction and overall increased with increasing reaction time. The result for ethyl valerate suggested that the reaction proceed rapidly within 45 minutes $(77.7 \%)$. There after, the percentage conversion remains at 90 minutes (77.53\%) and slightly decreased at 120 minutes (76.07\%). For nonyl caprylate, the percentage conversion shows a different profile where the reaction take about 5 hours to achieve equilibrium with percentage conversion $(87.98 \%)$. The percentage conversion shows high increment at 6 hours $(88.5 \%)$. However the conversion has decreased back at 8 hours (85. 20\%). This was due to the production of water molecule, which had achieved the equilibrium state. As the reaction proceeds, the substrates concentration decreased which led to a fall in the degree of saturation of the enzyme with substrate.

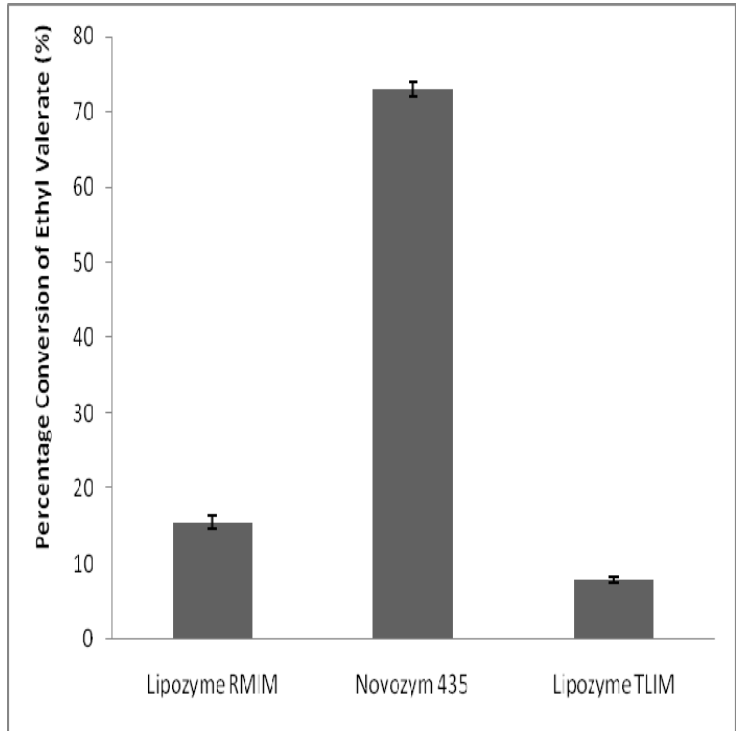

(a)

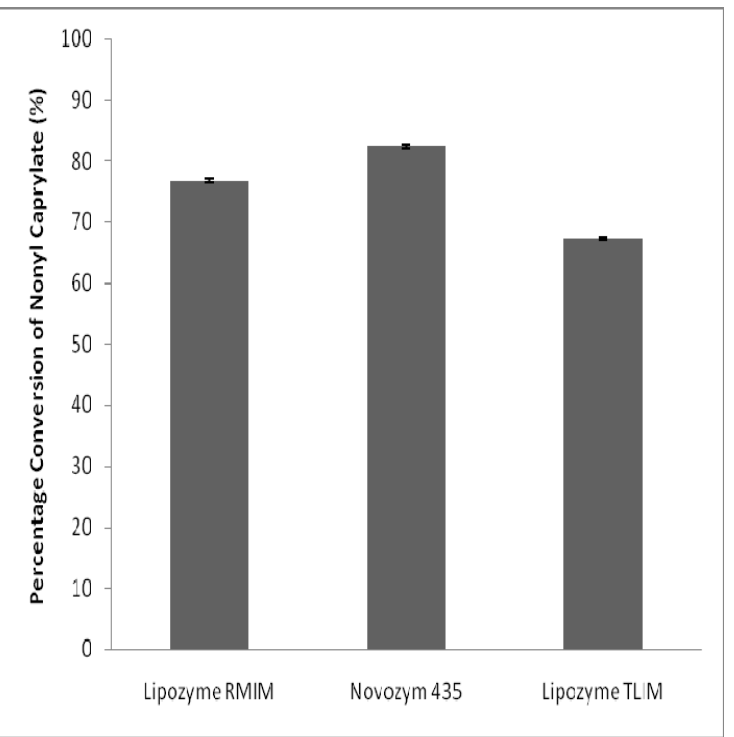

(b)

Figure 1: Effect of different types of immobilized lipase on the synthesis of ethyl valerate (a) and nonyl caprylate (b). Reaction condition: reaction time; 24 hours, temperature; $37^{\circ} \mathrm{C}$, amount of enzyme; $5 \%(\mathrm{w} / \mathrm{w})$ and agitation speed of $150 \mathrm{rpm}$.

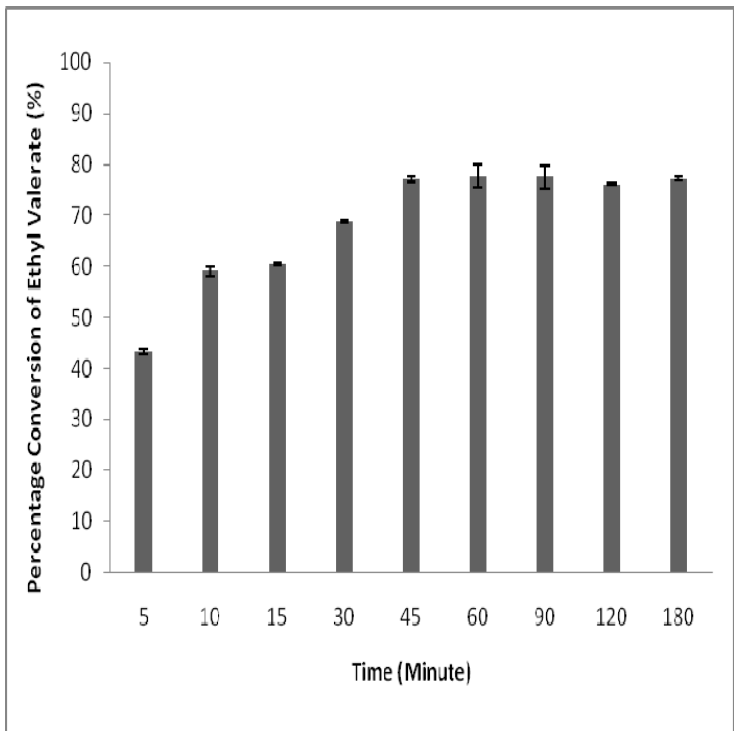

(a)

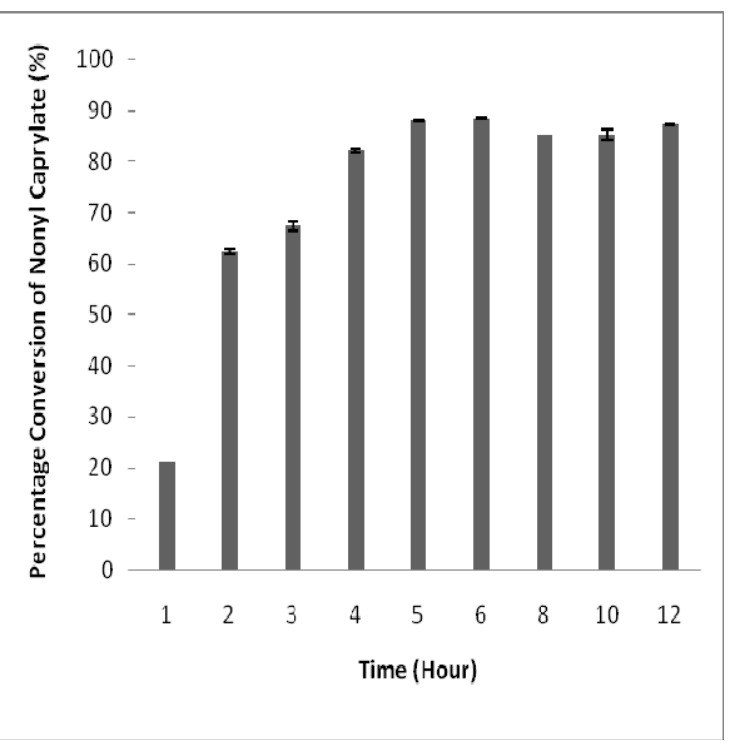

(b)

Figure 2: Effect of reaction time on the synthesis of ethyl valerate (a) and nonyl caprylate (b). Reaction condition: temperature; $37^{\circ} \mathrm{C}$, amount of enzyme; $5 \%(\mathrm{w} / \mathrm{w})$ and agitation speed of $150 \mathrm{rpm}$. 
S.K. Muhamad et al. / Journal of Fundamental Sciences Vol. 6, No. 1 (2010) 31-36.

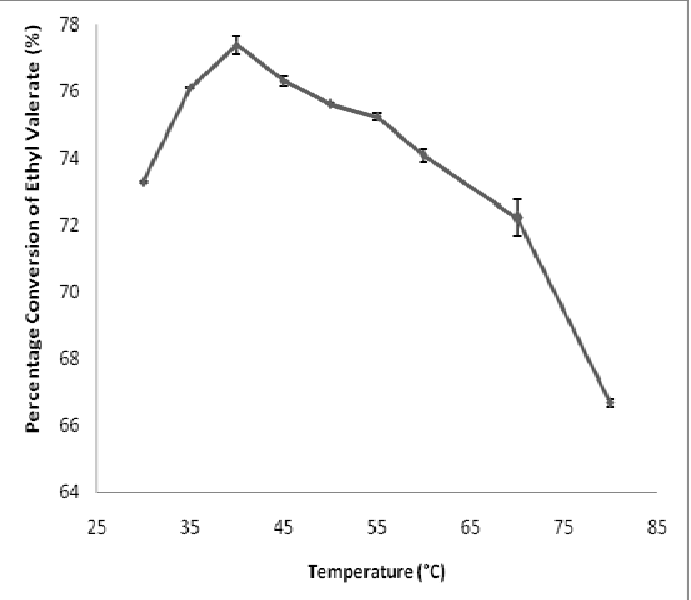

(a)

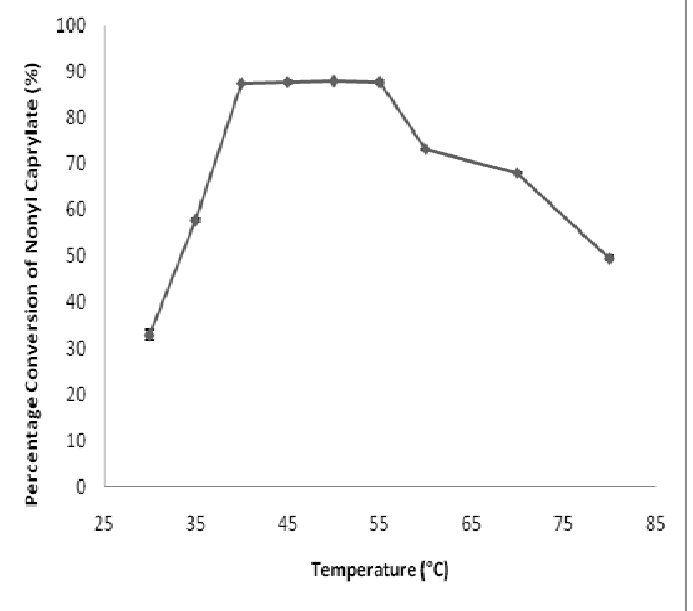

(b)

Figure 3: Effect of reaction temperature on the synthesis of ethyl valerate and nonyl caprylate. Reaction condition: reaction time; 2 hours, amount of enzyme; $5 \%(\mathrm{w} / \mathrm{w})$ and agitation speed of $150 \mathrm{rpm}$.

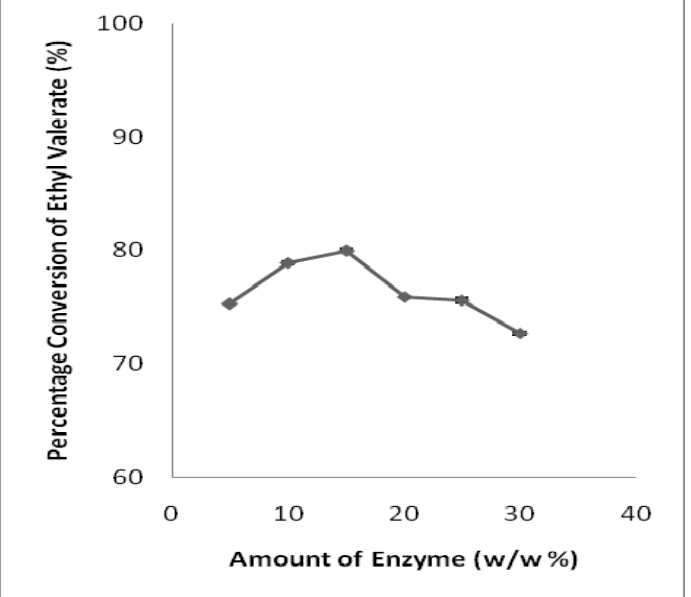

(a)

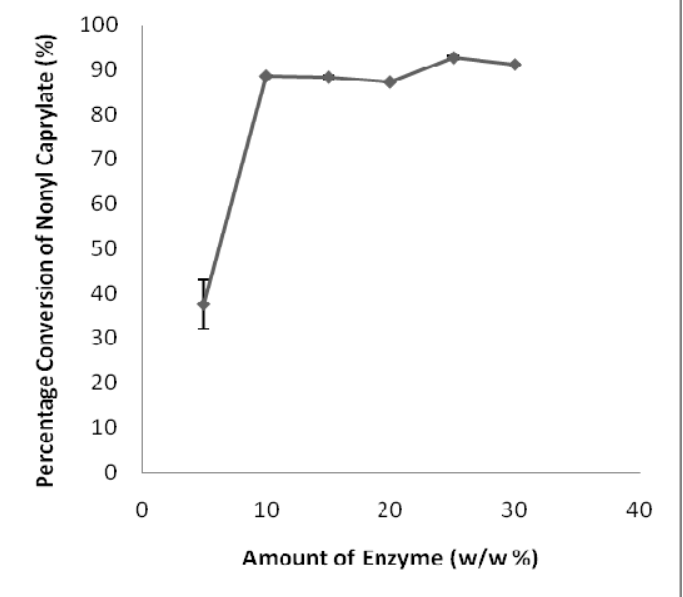

(b)

Figure 4: Effect of amount of enzyme (w/w) on the synthesis of ethyl valerate (a) and nonyl caprylate (b). Reaction condition: reaction time; 2 hours, reaction temperature; $37^{\circ} \mathrm{C}$ and agitation speed of $150 \mathrm{rpm}$.

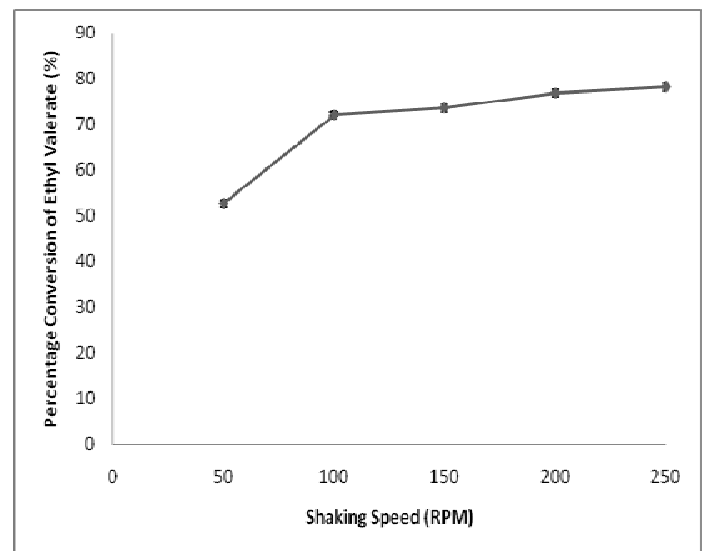

(a)

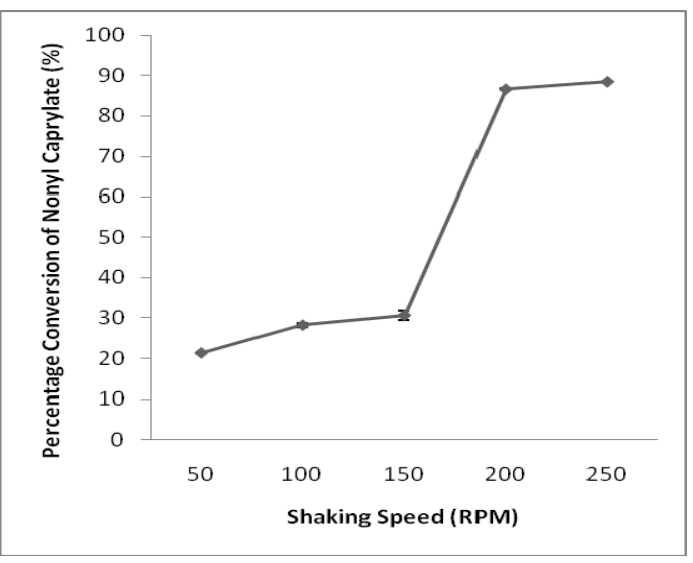

(b)

Figure 5: Effect of shaking speed on the synthesis of ethyl valerate (a) and nonyl caprylate (b). Reaction condition: reaction time; 2 hours, reaction temperature; $37^{\circ} \mathrm{C}$ and amount of enzyme $5 \%(w / w)$. 


\subsection{Effect of temperature}

Changes in the reaction temperature can affect the activity and stability of the enzyme and thus the rate of reaction. Effect of temperature also can be apportioned to its effect on substrate solubility as well as its direct influences on the esterification reaction and the enzyme. Figure 3 shows the influence of temperature on the esterification reaction within temperature range between 30 $-80^{\circ} \mathrm{C}$ for ethyl valerate and nonyl caprylate.

Initially, the percentage conversion for ethyl valerate increased with increasing temperature from $30{ }^{\circ} \mathrm{C}(73.29 \%)$ to $40{ }^{\circ} \mathrm{C}(77.39 \%)$. This due to the fact that, energy received from heat of higher temperature was used to increase the frequency of collision between the molecules. The percentage conversion was slightly decreased at range of $45^{\circ} \mathrm{C}-55^{\circ} \mathrm{C}$ and decreased sharply at $70{ }^{\circ} \mathrm{C}$ to $80{ }^{\circ} \mathrm{C}$ (66.65\%). An increment in the reaction temperature improved the substrates solubility and dissociation and decrease in the binding equilibrium, leading to unfavorable esterification conditions [9].

The conversion for nonyl caprylate also demonstrated the positive effect on the temperature in the esterification reaction. The percentage increased with increasing temperature from $30{ }^{\circ} \mathrm{C}(32.86 \%)$ to $40{ }^{\circ} \mathrm{C}$ $(87.47 \%)$. High percentage conversion is also attributed to the enzyme immobilization, which has conferring stability to the lipase. Novozym 435 is a lipase from Candida antartica immobilized on a microporous acrylic resin is a tolerance product with maximum activity in the high temperature $\left(40-60{ }^{\circ} \mathrm{C}\right)$. On the other hand, the percentage conversion of nonyl caprylate remains unchanged till $55^{\circ} \mathrm{C}$ (87.65\%). The percentage conversion was sharply dropped at $60{ }^{\circ} \mathrm{C}(73.1 \%)$. This is probably because beyond a critical temperature, the enzyme molecule will unfold and altered its tertiary and quaternary structure (threedimensional conformation). Consequently, the catalytic energy of lipase will reduce due to the denaturation process occurred [10].

\subsection{Effect of amount of enzyme}

From an applied point of reaction, the substrate concentration should be as high as possible to obtain a higher degree of esterification. Simultaneously, the amount of immobilized enzyme used should be as low as necessary to obtain the desired product. Amount of enzyme plays a crucial role in any biocatalytic process especially in large scale production. Its influence on the reaction was therefore assessed to facilitate determination of the minimal amount necessary for achieving goods yield.

The influence of varying amount of enzyme corresponding from 5 to $30 \%(\mathrm{w} / \mathrm{w})$ on the esterification reaction of valeric acid with ethanol and caprylic acid with nonanol is shown in Figure 4. For ethyl valerate, the percent of conversion illustrated constant increased from 5 (75.3\%) to $15 \%(\mathrm{w} / \mathrm{w})(80.0 \%)$. The increase in enzyme amount affected the percentage conversion and slightly decreased at
$20 \%(75.9 \%)$ and finally dropped to $72.7 \%$ at $30 \%$ of enzyme amount. In addition, the percentage conversion of nonyl caprylate showed a small difference. It had increased from $5(37.7 \%)$ to $10 \%$ (w/w) (88.6\%) and kept constant when the amount of enzyme increased untill $25 \%$ (92.7\%) before slightly decreased at $30 \%$ (91.2\%).

The result shows an excess of enzyme amount did not contribute to the increase in the percentage conversion. This is also similar with what was reported previously [11] and sometime it would decrease the yield of the product. At saturation point, all the substrates are bound to the enzyme and added enzyme molecule could not find any substrate to serve as a reactant. If the enzyme concentration is increased above this point, the reaction will slightly decline due to the steric hindrance produced by excessive enzyme. In such condition, the reaction can increase by increasing the substrate concentration, because substrate was the limiting factor. In esterification reaction, the amount of enzyme will influence the total reaction times, which are required to achieve desired conversion. The most significant main effect in enzymatic esterification reaction is the initial catalyst concentration [12]. This effect has positive influence on ester yield.

\subsection{Effect of shaking speed}

To observe the effect of mass transfer limitations, the effect of shaking speed between $50 \mathrm{rpm}$ and $250 \mathrm{rpm}$ on reaction rates was studied. The results for different shaking speed are shown in Figure 5. The initial rate increased with the increasing of shaking speed. Above $100 \mathrm{rpm}$ (72.1\%) shaking speed, the conversion of ethyl valerate almost constant. In contrast with nonyl caprylate, it was found that the substrate conversion increased progressively to reach a maximum at $200 \mathrm{rpm}$ (86.5 \%), beyond which the conversion remained unchanged [13].

Minimum mass transfer resistance was noticed at 100 rpm for ethyl valerate and $200 \mathrm{rpm}$ for nonyl caprylate which did not further increase upon increasing the shaking speed. Shaking speed play a major role in a molecule movement. Higher shaking speed can increase the movement of molecules, thus resulting the high combination of enzyme to substrates. Moreover, it will also increase external mass transfer rates between the bulk phase of the reaction mixture and the surface of enzyme

\section{CONCLUSION}

Four parameters were chosen to optimize the synthesis of flavour esters, namely reaction time, temperature, amount of enzyme and shaking speed. A maximum percentage for nonyl caprylate of more than $90 \%$ in a solvent-free system was obtained at reaction time (RT) of 5 hours, reaction temperature of $40{ }^{\circ} \mathrm{C}$, amount of immobilized lipase of $25 \% \mathrm{w} / \mathrm{w}$ of total substrate and shaking speed of $200 \mathrm{rpm}$. Compared to ethyl valerate, a maximum percentage conversion of more than $80 \%$ in 
solvent free system was obtained at reaction time (RT) of 45 minutes, reaction temperature of $40{ }^{\circ} \mathrm{C}$; amount of immobilized lipase of $15 \% \mathrm{w} / \mathrm{w}$ of total substrate and shaking speed of 200rpm. This work suggests that flavour esters can be produced at a very high yield and in a short period by lipase-catalyzed reactions. The high percentage conversion is also essential for possible large scale synthesis.

\section{ACKNOWLEDGEMENT}

We acknowledge financial support from the Ministry of Higher Education Malaysia via FRGS grant and NSF grant for S.K. Muhamad.

\section{REFERENCES}

[1] L.L.M.M. Melo, G.M. Pastore and G.A. Macedo, Process Biochem., 40 (2005) 3181-3185.

[2] R.B.Salah, H. Ghamghui, N. Miled, H. Mejdoub and Y. Gaigouri, J. Biosci. Bioeng., 4 (2007) 368-372.

[3] S.W.Chang, J.F. Shaw, C.K. Yang and C.J. Shieh, Process Biochem., 42 (2007) 1362-1366.

[4] M.K. Chaabouni, H.Ghamgui, S.Bexxine, A.Rekik and Y. Gargouri, Process Biochem., 41 (2006) 1692-1698.

[5] K. B. Vaidya, G. C. Ingavle, S. Porantham, B.D.Kulkarni and S.N.Nene, Bioresour. Technol., 99 (2008) $3623-3629$.

[6] M.Petkar, A.Lali, P.Caimi and M.Daminati, J. Mol. Catal., B Enzym., 39 (2006) 83-90

[7] G. Trubiano, D.Borio, and A.Errazu, Enzyme Microb. Technol., 40 (2007) 716-722.

[8] J.Aracil, M.Martinez, and N.Sanchez, Zeolites., 26 (1992) 233-236.

[9] M.B. Abdul Rahman, U.H. Zaidan, M. Basri, M.Z. Hussein, R.N.Z.R. Abdul Rahman and A.B. Salleh, J. Mol. Catal., B Enzym., 50 (2008) 33-39

[10] R.M.James and M.Trudy, Biochemistry, (2003) 163-164.

[11] Torres, Carlos, Otero and Cristina, Enzyme Microb. Technol., 29 (2001) 3-12.

[12] J.Aracil, N.Sanchez, M.Martinez and A.Corma, J. Am. Oil Chem. Soc., 69 (1993) 1150-1153

[13] P.Mahapatra, A.Kumari, V.K.Garlapati, R.Banerjee and A.Nag, J. Mol. Catal., B Enzym., 60 (2009) 57-63 